\title{
A desconstrução do conceito de dislexia: conflito entre verdades ${ }^{1}$
}

\author{
Giselle Massi ${ }^{2}$ \\ Universidade Tuiuti do Paraná, Curitiba-PR, Brasil \\ Ana Paula de Oliveira Santana \\ Universidade Federal de Santa Catarina, Florianópolis-SC, Brasil
}

\begin{abstract}
Resumo: Neste artigo discute-se a desconstrução do conceito de dislexia que se situa em dois polos: nas ciências da saúde que apresentam como causas da dislexia fatores orgânicos (funcionamento cerebral, fatores genéticos, dificuldades cognitivas) e nas ciências humanas, causas ligadas a fatores sociais (letramento, singularidades, fatores educacionais) cujas implicações recaem sobre dificuldades das crianças. Em um polo, há a construção de uma patologia, no outro, sua desconstrução por meio de conceitos como heterogeneidade e diferenças socioculturais. Trata-se de discussão relevante uma vez que os profissionais que trabalham nessas áreas tornam-se "cúmplices" ou "críticos" de uma dessas interpretações da realidade.
\end{abstract}

Palavras-chave: dislexia, linguagem, clínica.

\section{The deconstruction of the dyslexia concept: conflict between different perspectives}

\begin{abstract}
This paper discusses the deconstruction of the concept of dyslexia, constructed around two axes: the health sciences, which present organic factors as causes of dyslexia (brain functioning, genetic factors, cognitive difficulties) and human sciences, which link causes to social factors (literacy, singularities, educational factors) whose implications result in children's difficulties. There is, in one of the axes, the construction of pathology, and in the other, its deconstruction through concepts such as diversity, and social and cultural differences. This discussion is relevant because professionals working in these fields become either "accomplices" or "critics" of one of these interpretations of reality.
\end{abstract}

Keywords: dyslexia, language, clinic.

\section{La desconstrucción de la noción de dislexia: conflicto entre verdades}

\begin{abstract}
Resumen: En este trabajo se discute la desconstrucción del concepto de dislexia. Esta discusión se estructura en torno a dos polos: en las ciencias de la salud, que presentan como causas de la dislexia factores orgánicos (función cerebral, factores genéticos, dificultades cognitivas) y, en las ciencias humanas, causas ligadas a factores sociales (alfabetización, singularidades, factores educativos) que tienen consecuencias directas para las dificultades de los niños. La notable diferencia es que, por un lado, tenemos la construcción de una patología y, por otro, su desconstrucción a través de conceptos como heterogeneidad y diferencias socioculturales. Esta discusión es importante ya que los profesionales que trabajan en estas áreas se vuelven "cómplices" o "críticos" de una de estas interpretaciones de la realidad.
\end{abstract}

Palabras clave: dislexia, lenguaje, clínica.

A dislexia vem sendo descrita na literatura como uma dificuldade no processo de aprendizagem da leitura e da escrita (Blasi, 2006). Caracteriza-se por uma leitura e escrita marcadas por trocas, omissões, junções e aglutinações de grafemas; confusão entre letras de formas vizinhas, como em mato por nato; confusão entre letras relacionadas a produções fonéticas semelhantes, como em trode por trote, popre por pobre, galçada por calçada; omissão de letras e/ou sílabas, como em entrando por encontrando, gera por guerra; adição de letras e/ou sílabas como, por exemplo, em muimto por muito ou guato por gato; união de uma ou mais palavras e divisão inadequada de vocábulos, como é possível verificar em eraumaves (era uma vez) e a mi versario (aniversário) (Massi, 2007).

\footnotetext{
${ }^{1}$ Este texto foi revisado seguindo Acordo Ortográfico da Língua Portuguesa (1990), em vigor a partir de $1^{\circ}$ de janeiro de 2009.

${ }^{2}$ Endereço para correspondência:

Giselle Massi. Rua Benjamin Lins, 750/apto. 61. CEP 80.420-100.

Curitiba-PR, Brasil.E-mail: giselle.massi@hotmail.com
}

As explicações para esses fatos têm duas bases: uma fundamentada nas ciências da saúde que geralmente tomam esses fatos linguísticos como sintomas de uma patologia ligada ao funcionamento neurobiológico e/ou neuropsicológico buscando elucidá-los em função de padrões de "normalidade", conforme acompanhamos em Capovilla e Capovilla (2004), Ianhez e Nico (2002), Santos (1987), dentre outros. Nesse caminho, segundo Kassar (2000), a partir da incorporação do pensamento "naturalista" pelas ciências humanas, o desenvolvimento do aluno é visto tal qual ocorre com as plantas, ou seja, como um "desabrochar" de dons e qualidades. O mau desempenho do aprendiz é justificado em função dele próprio que acaba por carregar a culpa de seu "fracasso" e de sua "incapacidade" para aprender.

A outra explicação é fundamentada nas ciências humanas que entendem esses mesmos fatos como previsíveis no processo de aquisição da escrita. Para isso, distanciam-se de uma noção patologizadora e aproximam-se de explicações de cunho social, de acordo com Abaurre, Fiad e MayrinkSabinson (1997), Cagliari (1998) e Massi (2007). Esse olhar 
interpreta os fatos linguísticos, como parte do processo de aquisição, que estariam mais relacionados às práticas de letramento dos sujeitos. O mau desempenho do aprendiz é justificado pelas condições restritas de letramento de sua família e professores, pelos métodos de alfabetização, pelo significado da escrita para ele, seus professores e familiares. Esses fatores corroboram a noção de incapacidade do sujeito diante da escrita e, consequentemente, fundamentam a noção derivada de uma trajetória que se resume a um "fracasso escolar". Nas palavras de Mello (2010, p. 11) "a escola não aceita a criança como ela é e a criança não aceita a escola tal como ela funciona".

A discussão que pretendemos desenvolver neste artigo recai sobre a interpretação de determinados sintomas tanto por uma área, as ciências da saúde, quanto por outra, as ciências humanas. Para Foucault (2001), a doença apresenta-se por meio de uma coleção de sintomas. É a intervenção de uma consciência que transforma o sintoma em signo, que significa. O olhar do clínico, "sensível" à diferença, à simultaneidade, à sucessão e à frequência, é capaz de descobrir segredos e alcançar a "verdade". A sensibilidade do clínico deve ser capaz de desvendar a doença, conhecer sua natureza, suas complicações, determinar quando é preciso agir, quando é preciso esperar, decidir sobre os métodos que oferecem vantagens e os que são mais inconvenientes. Assim, a clínica pede um olhar que vê, que classifica e que reconhece identidades.

A clínica, ressalta Foucault (1994), não se caracteriza por um espaço em que se descobrem "verdades" desconhecidas, mas por uma maneira de dispor "verdades" já adquiridas e de apresentá-las. Nesses termos, a clínica afirma-se enquanto um espaço disciplinar. E a disciplina está diretamente relacionada à autoridade, ao olhar hierárquico, à sanção normatizadora e sua combinação: o exame.

Portanto, o exame é o instrumento que mede aquele que se afasta ou não da norma. Uma norma que é definida não apenas socialmente (Canguilhem, 1995), mas também está relacionada a questões de poder (Foucault, 1994). A norma submete as pessoas a determinados modelos, gestos e comportamentos. Seu espaço é homogêneo, diante do qual todos devem ser iguais.

Quanto maior a "individualidade" de alguém, quanto mais ele explicita as suas características singulares, mais ele se distancia da norma, ou seja, do que é aceito por dada sociedade como normal. Os conceitos de normal e patológico estão ligados tanto a questões sociais quanto a questões de poder. É nesse campo do poder que uma instituição define o que passa a ser doença e saúde, que classifica, que nomeia os signos e os significa, transformando-os em doença.

Assim, é possível afirmar que o surgimento de uma "patologia" e de seus "sintomas" está relacionado não só a questões de saúde, mas também a questões sociais. Não há uma proposta imparcial, pois qualquer proposta está, inevitavelmente, refletindo diferentes concepções sobre o modo de conceber a doença e a saúde, o normal e o patológico. Essas diferentes concepções resultam da forma que cada clínico/ pesquisador interpreta os signos que analisa, seja como parte de um distúrbio, seja como parte de um processo singular.

Essas formas diversas de explicar/analisar fenômenos patológicos podem ser percebidas quando o contexto da aquisição da escrita passa a ser também um contexto "clínico". Para explicar e analisar fatos linguísticos apresentados por crianças durante o processo de aquisição da escrita, atualmente, é possível perceber, no mínimo, duas posições distintas no contexto clínico: uma delas que toma tais fatos como sintomas de um distúrbio e outra que os toma como parte do processo de aquisição da escrita.

Essa diferença ocorre, tendo por base duas concepções: uma fundamentada na saúde que busca a etiologia no orgânico; outra que entende o sujeito e suas ações - inclusive as linguísticas - vinculando-os às práticas sociais. De um lado, estão a medicina e as áreas que assumem um pressuposto teórico organicista, como determinadas vertentes da fonoaudiologia, da psicologia, a neuropsicologia, e, de outro lado, a linguística, a educação e outras vertentes da fonoaudiologia que se baseiam em fundamentos teóricos discursivos.

Fijalkow e Ragano (2004) fizeram essa discussão considerando as políticas educacionais da França. Eles afirmam que estudos da psicologia escolar e das ciências humanas, depois da Segunda Guerra Mundial, iniciaram um debate de contestação da natureza orgânica das dificuldades de escrita. Os autores afirmam haver uma "disputa" teórico-política, entre a medicina e as ciências cognitivas, que postula que as condutas humanas são biologicamente naturais, e as ciências sociais e humanas que levam em conta fatores sociais e pedagógicos, partindo de teorias construtivistas e sócio-históricas. A dislexia é um problema não apenas biológico, mas social. De acordo com Fijalkow e Ragano (2004, p. 183): “a etiqueta dislexia quando aparece no início da escolaridade marca sob a etiqueta médica um problema social".

Partindo dessas considerações, o objetivo deste artigo é propor uma discussão do conceito de dislexia, levando em conta essas duas posições antagônicas: uma da área da saúde e outra da área social. Faremos isso a partir de revisão bibliográfica.

\section{A constatação dos sintomas pelas ciências da saúde}

\section{As dificuldades de aquisição da escrita e a relação com as afasias}

Em 1896, um menino de 14 anos de idade chamado Percy, instigado por sua dificuldade para aprender a ler e a escrever, consultou um médico e lhe disse que, embora fosse inteligente, não conseguia aprender a ler e escrever. Esse menino não sabia o alfabeto e apresentava erros ao grafar as palavras. O médico que o atendeu foi o inglês Pringle Morgan que, verificando suas dificuldades, apesar de ter visão normal, diagnosticou-o como portador de "cegueira verbal congênita”, marcando o surgimento da categorização de um 
distúrbio de aprendizagem - a dislexia - como patologia resultante de lesão cortical. Tal diagnóstico, porém, foi influenciado por estudos realizados com adultos que apresentavam transtornos na escrita, após sofrerem uma lesão cortical localizada, conforme Quirós e Della Cella (1972).

Hinshelwood, ciente do caso descrito por Pringle Morgan, propôs, em 1917, que dificuldades relativas à aprendizagem da escrita poderiam ser explicadas em função de um suposto dano congênito do giro angular, localizado na zona póstero-inferior do lóbulo temporal. Portanto, originalmente, o interesse em estudar e explicar questões relativas ao processo de aquisição da escrita e suas "dificuldades" vinculava-se à área médica que tomou como referência pesquisas afasiológicas localizacionistas, que se pautavam em casos patológicos de adultos que, em função de lesões neurológicas, tiveram alterada a capacidade para ler e escrever (Freire, 1997).

A localização de funções mentais no cérebro humano vigorou entre os interesses teóricos da última metade do século XIX. Os primeiros estudos científicos de pacientes com problemas adquiridos de linguagem surgiram com a apresentação de Paul Broca na Sociedade de Antropologia de Paris, em 1861 (Broca, 1965). Com relação à escrita, ganharam destaque os estudos de Déjèrine (1891) sobre as afasias (alexias e agrafias). Déjèrine descreveu a participação da área parieto-temporal na leitura e na escrita e criticou a ideia de um centro específico da escrita. Essa hipótese vem sendo corroborada até os dias de hoje. Contudo, com mais objetividade, graças aos avanços dos exames neurológicos, como o PET (Positron Emission Tomography). Acrescente-se que, desde a década de 1970, Luria (1970) apresenta sua hipótese de Sistema Funcional Complexo. Segundo essa teoria, não existe área cerebral específica para as funções cognitivas superiores, mas um trabalho entre várias áreas cerebrais.

Segundo Lyan, Shaywitz e Shaywitz (2003), a maior evidência da base neurobiológica da dislexia deu-se justamente a partir das pesquisas com neuroimagem que encontraram diferenças nas regiões parieto-têmporo-occipital entre sujeitos disléxicos e não disléxicos. $\mathrm{O}$ autor ressalta que as pesquisas têm documentado uma disruptura do sistema neural para a leitura na dislexia que independe de questões linguísticas e culturais, assim como evidências de falhas no hemisfério esquerdo posterior. Podemos concluir, assim, que há mais de um século a medicina tem investido em pesquisas que apontam aspectos neurobiológicos como causadores da dislexia. Ou seja, a discussão que se iniciou nas afasias e, portanto, com a lesão cerebral, passou hoje para questões relacionadas à disfunção ou a falhas no processamento (Arduini, Capellini, \& Ciasca, 2006).

Com relação à semiologia das alterações da linguagem escrita, observamos uma verdadeira floresta terminológica e uma grande confusão conceitual em torno dessas alterações. A variedade de denominações utilizadas para a classificação desse distúrbio já é amplamente conhecida: agrafia, dislexia de superfície, dislexia profunda, dislexia adquirida, dislexia fonológica, entre outras (Santana, 2002). Segundo Salles, Parente e Machado (2004), são tantas as nomenclaturas que é difícil saber se os autores estão se referindo à mesma síndrome.

De acordo com Massi (2004), foi em função da descrição de sintomas afásicos em adultos que surgiu o conceito de dislexia relacionado às dificuldades de aquisição de escrita nas crianças. Eventos tais como trocas de letras, escrita espelhada, segmentação de vocábulos, omissão de sílabas, entre outros, foram associados a nomenclaturas médicas: dislexia específica de evolução, transtorno específico da língua escrita, dificuldade de leitura e escrita ou, simplesmente, dislexia.

Assim, se, inicialmente, a dislexia vinculada ao processo de aquisição da escrita aproximou-se das afasias pela semelhança de fatos compreendidos como sintomas, em um segundo momento ela alcançou seu estatuto de patologia diferente da "dislexia adquirida", relacionada às afasias, pelo afastamento da causa orgânica: a lesão cerebral. Vejamos, na sequência, as causas propostas para o que tem sido tomado como dislexia ou distúrbio de aprendizagem escrita.

\section{As causas de natureza individual}

Para Orton, os distúrbios na aprendizagem da escrita apresentados por uma criança em fase de alfabetização deveriam ser compreendidos diferentemente de transtornos adquiridos e manifestados pelo adulto. Após examinar cerca de três mil crianças com dificuldades relativas à leitura e à ortografia, Orton afirmou, em 1925, que distúrbios de aprendizagem da escrita, na infância, estariam relacionados a um defeito no reconhecimento da orientação das letras e de sua sequência nas palavras, ressaltando que, apesar de apresentarem problemas na escrita, a percepção visual e a orientação espacial dos sujeitos examinados mostravam-se intactas (Grégoire e Piérart, 1997).

No seu entendimento, esse defeito era decorrente de uma falha no desenvolvimento da dominância hemisférica cerebral. Por isso, propôs o uso do termo "estrefossimbolia" - que significa simbolização distorcida -, acentuando uma característica que julgava fundamental: a produção de letras invertidas. Assim, Orton buscou substituir a denominação anteriormente dada, "cegueira verbal congênita", pois, no seu ponto de vista, tratava-se de uma anomalia de predomínio hemisférico e não de lesão cerebral focal.

As pesquisas atuais afastam-se da ideia de lesão e trabalham com a hipótese de disfunção. Para Hout (2001), crianças diagnosticadas como disléxicas teriam anomalias na mobilidade dos olhos. Castro, Salgado, Andrade, Ciasca e Carvalho (2008) consideram que a dislexia de desenvolvimento estaria ligada a déficits da via visual magnocelular e uma parte da rede cortical posterior da atenção, envolvendo áreas corticais e movimento ocular. Condemarin e Blomquist (1986) apontam para fatores hereditários. Bates e cols. (2009) apontam causas relacionadas a mutações genéticas. Galaburda, LoTurco, Ramus, Fitch e Rosen (2006) 
diagnosticaram quatro genes associados à dislexia, responsáveis pelos transtornos de migração celular e do crescimento de axônios, levando à criação de circuitos anormais entre o córtex e o tálamo e à alteração de funções sensório-motoras, perceptuais e cognitivas, importantes para a aquisição da leitura.

Nessa direção, deficiências cognitivas seriam tomadas como causa da dislexia e poderiam afetar, de acordo com Ajuriaguerra (1984), diferentes processos envolvidos na construção da escrita: percepção visual, percepção auditiva, estruturação espaço-temporal. Seguindo a trilha de hipóteses cognitivistas, podemos citar Fonseca (1995), para quem a integração cerebral de subsistemas psicomotrizes faria emergir movimentos responsáveis pela escrita de uma letra. No seu entendimento, sintomas disléxicos poderiam ser tomados como consequência de desordens psicomotoras.

Já para Critchley (1974) crianças disléxicas têm um retardo na maturação cerebral. Para esse autor, deficiências em certas funções cerebrais estariam relacionadas a problemas maturacionais, ocasionando limitações no processo de alfabetização. Por fim, pesquisas associadas ao enfoque cognitivista propõem que dificuldades de aprendizagem da escrita seriam decorrentes de uma disfunção cerebral mínima. Tal disfunção, caracterizada por anormalidades de neurotransmissores, originaria distúrbios no comportamento infantil descritos como parte de uma síndrome hipercinética que, por sua vez, ocasionaria distúrbios relacionados à aprendizagem da leitura e da escrita.

Porém, com todas as hipóteses apresentadas, essa explicação não ultrapassa o plano de suposições. Aliás, segundo Selikowitz (2001), a noção de disfunção cerebral mínima vem sendo criticada pelo fato de ter despertado a possibilidade de fazer uso de medicamentos para "corrigir" uma hipotética desordem química no cérebro.

Uma das mais recentes explicações para a dislexia toma como fator etiológico a dificuldade de consciência fonológica. A neuropsicologia cognitiva e uma parte da fonoaudiologia vêm embasando seu trabalho terapêutico nesse pressuposto. A dislexia, nesse caso, seria um distúrbio específico de linguagem caracterizado pela dificuldade em decodificar palavras isoladas. A hipótese é de que há uma simetria nos planos temporais em $70 \%$ dos disléxicos e decorre do resultado de testes aplicados a sujeitos disléxicos. Esses sujeitos apresentaram maior dificuldade para memória verbal, repetição de pseudopalavras, consciência fonêmica, como, por exemplo, a segmentação da fala em fonemas (Capovilla \& Capovilla, 2004).

Há ainda autores, como Blasi (2006), que, embora reconheçam o vínculo entre dislexia, consciência fonológica e representação gráfica dos sons da língua, argumentam ser um equívoco que a dificuldade ou ausência da consciência fonológica seja a causa da dislexia, considerando o fato de que essa dificuldade de consciência fonológica acontece porque os indivíduos não dominam o sistema alfabético, ferramenta necessária para manipular os fonemas.
Outro aspecto, ligado à audição e que vem sendo atribuído como causa da dislexia, é a dificuldade de processamento auditivo central (Sauer, Pereira, Ciasca, Pestun, \& Guerreiro, 2006). A hipótese é de que as crianças teriam dificuldade em processos de decodificação e transformação das ondas sonoras, desde a orelha externa até o córtex auditivo, envolvendo a detecção e interpretação dos sons, capacidade de identificar eventos sonoros, realização de figura/fundo, reconhecimento, categorização e atribuição de significado às informações acústicas (Capovilla, 2004).

Estudos mais recentes, embora considerem déficits de processamento temporal, déficits de processamento visual e auditivo como possíveis causas da dislexia, apontam o modelo do déficit fonológico como o mais aceito na atualidade. Segundo Lopez-Escribano (2007), os estudos de neuroimagem mostram ativação cerebral atípica em disléxicos, durante tarefas que requerem processamentos fonológicos.

Arduini, Capellini e Ciasca (2006), a partir de exames de neuroimagem de crianças com diagnóstico de dislexia, encontraram diferenças significativas relacionadas à hipoperfusão nas áreas envolvidas nos processos de leitura e de escrita. Segundo Novaes Pinto (2008), vemos, na atualidade, uma vasta quantidade de trabalhos produzidos nas neurociências que têm como objetivo não só postular "modelos de processamento linguístico", mas revelar os substratos neurais que participam dos processos funcionais complexos como linguagem, o que parece se constituir como uma tendência neolocalizacionista ou neofrenológica. Para a autora, ao contrário das primitivas técnicas utilizadas por Gall, no século XIX, que apalpava os cérebros dos pacientes nas autópsias a fim de descobrir protuberâncias ou lesões que justificassem o estabelecimento de seus mapas frenológicos, a utilização da neuroimagem se estabelece no século XXI como o instrumento mais respeitado para revelar as "verdades" acerca do funcionamento cerebral.

Acompanhamos, assim, explicações neurológicas, genéticas, metabólicas, oftalmológicas as quais tendem a associar questões referentes à construção da linguagem escrita com defasagens orgânicas. Essas explicações denunciam um modelo de ciência que, ao estudar o ser humano, conformase aos preceitos das ciências naturais, fazendo com que as atividades humanas sejam percebidas como propriedades localizadas no organismo de indivíduos.

Ainda que de maneira breve, cabe comentar que a busca de uma explicação genética para questões da aprendizagem da escrita denuncia o fato de que uma visão biológica determinista está sendo usada para justificar características de atividades humanas como naturais, atribuindo à natureza orgânica questões escolares e, por aí, encobrindo diferenças humanas nos planos sociais e individuais. As desigualdades sociais e as diversidades no desempenho individual da criança são, nessa visão, interpretadas por meio de critérios orgânicos - inevitáveis e imutáveis -, garantindo que as análises do cotidiano escolar e do processo de apropriação da escrita permaneçam restritas ao signo da patologização individual. 
Nessa visão organicista, a ideia de lesão ou malformação orgânica é substituída pela noção de disfunção ou imaturidade cerebral. O que vemos é que os achados das pesquisas realizadas com neuroimagem influenciam terminologias relacionadas às síndromes neuropsicológicas em geral. Tais achados podem determinar mais fortemente a relação entre o orgânico e o psicológico, a partir da correlação estatística de uma função psicológica e uma área cerebral, fortalecendo os modelos que são valorizados pelo paradigma científico vigente nas neurociências.

Assim, podemos concluir que, no século XIX, a discussão da dislexia teve a área médica como precursora, especificamente a neurologia. E essa área continua a busca por fatores orgânicos, através dos exames de neuroimagem que marcam alterações encefálicas, estruturais e funcionais, capazes de ocasionar atrasos maturacionais, anomalias de células no córtex cerebral e anomalias genéticas. A partir da década de 1950, a psicologia entrou nessa discussão trazendo questões relativas a desordens psicomotoras e, no final do século XX, por meio da neuropsicologia, surgiram estudos apontando para um déficit de processamento fonológico da linguagem.

Em meio a essa noção normalizadora e homogeneizadora do corpo biológico, parece soar como "heresia" ou perigo colocar em xeque a noção de dislexia escolar tão divulgada e há muito tempo pesquisada pelas diversas áreas do saber. Questionar o conceito de dislexia pode significar um risco diante de uma perspectiva hegemônica acerca da temática.

A contrapartida disso é que os movimentos sociais surgidos em defesa dos disléxicos foram capazes, por um lado, de gerar Associações específicas para a defesa de seus direitos, tais como a Associação Brasileira de Dislexia, criada em 1983, e a Associação de Pais e Amigos dos Disléxicos (APAD), criada em 2004, e, por outro, foram capazes de manter e assegurar o estatuto de "doentes" para eles. A criação de leis para o atendimento do disléxico na área de educação especial (Lei 4.095/2008) acabou por legitimar o disléxico como portador de necessidades especiais. e continua influenciando estudos, pesquisas, bem como atividades profissionais envolvidas com essa temática em todo o nosso país, uma vez que o conceito divulgado na lei e por essas instituições é representativo da visão atual sobre o que tem sido entendido como dislexia.

\section{A constatação dos sintomas pelas ciências humanas}

\section{O processo de aquisição da escrita}

De acordo com Abaurre, Fiad e Mayrink-Sabinson (1997), os erros na escrita cometidos pelas crianças não são imperfeições decorrentes da não apropriação de um modelo de língua estático. Antes disso, os erros - tomados como estratégias de manipulação da linguagem - indicam o percurso percorrido pelo aprendiz na sua história de aquisição da escrita. Portanto, nessa ótica, os "desvios", as "inadequações" ou os "erros" cometidos pela criança, distantes de uma visão normalizadora e patologizadora, são indícios e pistas da própria efetivação da aquisição da escrita.

Esses indícios, que anunciam atividades que compõem o processo de apropriação da escrita, contrapõem-se à noção de "erro" como sintoma de uma doença, conforme proposto pela visão organicista. Para esses autores, a linguagem é concebida como atividade constitutiva (Franchi, 1992). A relação entre o sujeito e a linguagem se constitui e se modifica continuamente. A criança, durante a aprendizagem da escrita, constrói e reconstrói, em conjunto com o outro, estratégias muitas vezes episódicas para usar o objeto escrito.

De maneira geral, é possível destacar, dentre tais estudos, trabalhos desenvolvidos pela área da linguística por Abaurre, Mayrink-Sabinson e Fiad (2003), Abaurre (1994) e Cagliari $(1989,1998)$ que, envolvidos com dados singulares, explicitam inadequações de caráter formal e convencional da escrita, não como sintomas patológicos, mas como resultantes de reflexões lançadas pelos aprendizes sobre essa modalidade de linguagem.

Nessa visão, o "erro" é percebido como resultante de diferentes estratégias desenvolvidas pelo aprendiz durante a produção de textos. Dentre tais estratégias, ressaltamos: o uso "indevido" de letras em função do próprio sistema ortográfico que, em um dado contexto, aponta para um determinado uso e em outro não; a hipercorreção, isto é, a aplicação de uma regra indevidamente; o acréscimo, troca ou supressão de letras pelo fato de o aprendiz ainda não dominar o engendramento da escrita; a transcrição fonética, revelando que, muitas vezes, a criança escreve pautando-se em aspectos da oralidade; hipossegmentações e hipersegmentações, as quais denunciam que ora a criança faz fusões vocabulares por estar embasada no contínuo da fala e ora apresenta separações impróprias, exatamente pelo fato de já ter algum conhecimento acerca de convenções da escrita.

Nessa ótica, a construção dessa modalidade de linguagem implica um processo de reflexões constantes. Afinal, aprender a escrever significa cometer, de início, muitos erros resultantes de diferentes hipóteses lançadas sobre a escrita. Por isso, erros, trocas de letras, substituições, acréscimos, refacções, segmentações inadequadas, entre tantas outras "faltas" distantes da noção de dislexia, assumem o estatuto de indícios próprios do processo de apropriação da escrita.

Massi e Berberian (2005) asseveram que a aquisição da escrita não segue uma linearidade, e os seus "desvios" não são manifestações sintomáticas. Segundo as autoras, o diagnóstico de dislexia elaborado por profissionais da área da saúde se dá por critérios que desconsideram as dimensões sociais, restringindo historicamente o uso da escrita por uma parcela significativa da população.

Acompanhamos, nesse campo linguistas, fonoaudiólogos, sociólogos e educadores que discutem as dificuldades de apropriação da escrita, considerando questões relacionadas ao âmbito sociocultural (Berberian \& Massi, 2006; Lahire, 1997; Massi, 2007; Pan, 2006; Patto, 2010; Rojo, 2009). 
A discussão sobre as práticas de letramento dos alunos, de seus pais e professores é destacada no processo de apropriação da escrita pela criança (Kleiman \& Matencio, 2008; Ribeiro, 2004; Signorini, 2010). Estudos sobre o alfabetismo funcional no Brasil vêm demonstrando índices alarmantes de condições de letramento da população brasileira. Considerase analfabeto funcional a pessoa que, mesmo sabendo ler e escrever, não tem as habilidades de leitura, de escrita e de cálculo necessárias para viabilizar seu desenvolvimento pessoal e profissional.

De acordo com o Índice Nacional de Alfabetismo Funcional (INAF, 2007), apenas $28 \%$ da população brasileira tem plenas possibilidades de interpretar e produzir diferentes tipos de gêneros textuais. Dessa forma, o diagnóstico de dislexia geralmente dado para crianças que apresentam dificuldades no processo de aquisição sem fazer relação com suas condições de letramento e de sua família torna-se uma utopia.

Acrescentamos ainda que as crianças são consideradas disléxicas ou pré-disléxicas já nos primeiros anos escolares, sem que as práticas de letramento da família e o significado da escrita tenham sido considerados.

A partir de uma noção organicista, os sujeitos são vistos como indivíduos "homogêneos" que devem seguir, invariavelmente, o mesmo ritmo de aprendizagem. E a linguagem escrita fica diretamente relacionada apenas ao "bom" funcionamento cerebral. Essas concepções distanciam-se completamente de uma interpretação de cunho social, conforme apresentamos na sequência.

\section{Discussões acerca das questões sociais}

Estudos baseados em questões sociais e culturais para discutir os chamados sintomas disléxicos buscam explicar tais sintomas como previsíveis, a partir de pesquisas linguísticas acerca do processo de aquisição da linguagem (Massi, 2007). Além disso, procuram “desautorizar" a medicina e áreas afins - ou, ao menos, questionar sua "autoridade plena" - sobre a "verdade" de um diagnóstico de dislexia baseado no conhecimento teórico restrito que essas áreas têm sobre a linguagem e sobre o processo de aquisição da escrita. Ressaltemos que as ciências médicas, em seus currículos, pouco ou nada discutem sobre concepções de linguagem e de sujeito, sobre os processos linguísticos envolvidos na aprendizagem ou sobre mecanismos capazes de produzir desigualdades sociais e culturais.

Para Moysés e Collares (1992, p. 33), o raciocínio clínico tradicional, de modelo positivista, o qual parte do princípio de que "se A causa B, B só pode ser causado por A", levou as ciências médicas a supor que se uma lesão cerebral, em sujeitos adultos, pode ocasionar dificuldades para ler e escrever, então tais dificuldades, ainda que relacionadas a crianças que estão se apropriando da escrita, devem ser causadas por danos neurológicos.

Ressaltemos que a discussão da hipofunção cerebral também parte de uma determinada concepção de cérebro concebida a despeito das práticas sociais. Não negamos que exista uma hipofunção cerebral, tal fato, aliás, comprovado pelos estudos com neuroimagem. Negamos o fato de que a hipofunção seja a causa e não o efeito da ausência de práticas de letramento (Santana, 2007). Consideramos, em uma perspectiva sociocognitiva, a noção de que nosso cérebro é organizado a partir de nossas práticas sociais (Morato, 2006).

Outro ponto a discutir são pesquisas na área de genética que buscam relacionar doenças e genes, considerando apenas a questão biológica como preponderante na construção dos sintomas. $\mathrm{O}$ velho debate entre o social ou cultural e o biológico continua a existir e ainda está longe de ser esclarecido (Pinker, 2002). Até que ponto o social define e molda nossas características inatas? Segundo Befi-Lopes (2008), estudos sobre distúrbios específicos de linguagem (DEL) relacionando-os com atipicidade cerebral, ainda estão distantes da perfeição, uma vez que muitas crianças com DEL não apresentam atipias cerebrais. Parece, então, que tais atipias devem ser consideradas como fatores de risco para o desenvolvimento do distúrbio, mas sua natureza, severidade e persistência dependem, provavelmente, de fatores não biológicos, o que reforça a importância da descrição fenotípica como fator fundamental para a tentativa de se procurar o genótipo de tais quadros.

Uma criança que nasce em uma família que tem outros sujeitos com dificuldades de leitura e de escrita está fadada a receber o diagnóstico de disléxico. Berberian e Massi (2006) citam os seguintes comentários de mães de crianças disléxicas: "Ela puxou por mim. Eu tenho dislexia, ela também tem"; "Para eu entender os textos que tenho que ler na faculdade, eu tenho que ler várias vezes. Eu tenho essa dificuldade e ela também"; "Ele é preguiçoso. Quando ele se interessa, ele presta atenção". Esses discursos legitimam a dislexia na família, a partir do momento em que o diagnóstico é dado, e a criança parece, nesse sentido, ser uma cópia dos pais. O senso comum, com isso, transforma uma suposta herança social em herança natural.

O conceito de dislexia é, assim, legitimado em parte pelos profissionais e em parte pela própria família que toma as suas dificuldades com a linguagem escrita como sintomas de uma doença hereditária. Ou seja, é construído por um senso comum que, nesse contexto específico, recebe uma "chancela científica" autorizada pelo senso comum médico.

Entendemos que discussões distanciadas do contexto escolar e do entendimento do seu papel constitutivo, ao tomar aspectos da aprendizagem da escrita como decorrentes de um distúrbio, vêm se mostrando determinantes na propagação e perpetuação de um conceito vago e - cada vez mais - afastado de explicações capazes de esclarecer a natureza e a função social da escrita.

Segundo Massi (2007), a área médica, desprovida de conhecimentos específicos sobre a escrita bem como do sujeito-aprendiz, acaba por tomar inadvertidamente fatos que se apresentam no processo de aquisição como "sintomas" de uma categoria nosográfica geral, a qual chama de dislexia. 
Assim, pautada em uma orientação de cunho linguísticodiscursivo, a autora questiona a descrição que a medicina tradicional e demais áreas afiliadas a ela vêm tomando como sintomas associados ao que tem sido descrito como um distúrbio de aprendizagem da escrita.

Para Massi (2007), a subjetividade se constitui marcada por efeitos de sentidos discursivos. Ao ser apontada como alguém que está "fracassando" na escola diante da aprendizagem da escrita, é possível supor que qualquer criança pode apresentar uma baixa autoestima e pouco interesse pela escrita, sobretudo, quando a instituição escolar a enuncia como incapaz em função de hipóteses e "erros" que acompanham o processo de aprendizagem. Por isso, diante de um cenário etiológico tão diverso e contraditório, antes de conceber a criança como portadora de um distúrbio, Massi afirma ser imprescindível compreender o trajeto trilhado por ela para se apropriar da escrita, bem como os efeitos de práticas discursivas que circundam esse trajeto. Se a dislexia vem sendo entendida e definida como um distúrbio de linguagem, não é possível negar que a sua explicitação depende da diretriz de estudos linguísticos.

A criança, em uma perspectiva social e discursiva, constrói a sua subjetividade em função de suas interações sociais. A fala do outro a constitui como sujeito que é: "incompetente" diante da escrita. Por isso, são significativos os enunciados produzidos pelos pais e professores sobre e para a criança: "ele não sabe nada"; "ele não quer saber de estudar"; "ele é uma criança hiperativa"; "ele é igual ao pai que não conseguiu nem terminar a quarta série". Nesse sentido, o ritmo de aprendizagem e a idade não são tomados como fatores isolados e independentes das práticas sociais nas quais os sujeitos estão imersos. As interpretações, aqui, passam a ser de natureza social contrapondo-se à ótica organicista que apresenta hipóteses baseadas em impossibilidades que recaem sobre o indivíduo.

\section{Considerações finais}

Se a doença é uma coleção de sintomas, e o olhar do clínico transforma o sintoma em signo (Foucault, 2001), a dislexia, nesse sentido, é construída e desconstruída a partir de determinado olhar. O que procuramos, neste artigo, foi evidenciar que há uma luta permanente para definir a realidade através de uma "verdade". Essa luta abre espaço para que grupos produzam um saber autorizado para ser legitimado (Bourdieu, 1998). Ou seja, esse saber acaba por representar o que constitui a divisão entre o que é normal e o que é patológico.

Temos, assim, duas instâncias de interpretação: uma, vinculada às ciências médicas, que oficializa os "erros" da escrita de aprendizes como sintomas de uma patologia, a dislexia, ligada à noção de tempo e de aprendizagem "homogênea"; e outra, ligada às ciências humanas, que interpreta tais "erros" como parte do processo de aquisição da escrita e de letramento.
Por um lado, toma-se o desempenho escolar do aprendiz como resultante de habilidades intrínsecas a ele. Nesse caso, o sistema educacional associa o "fracasso" do aluno com a sua própria "incapacidade" de apropriar-se da escrita, determinando processos sociais de exclusão, de definição de doenças, de criação de associações e de leis especiais para os disléxicos. Por outro, sob a ótica que assume a linguagem como atividade constitutiva, partimos do pressuposto de que a relação sujeito/linguagem é permeada por aspectos intersubjetivos, os quais perpassam as relações sociais e escolares que são constituídas de subjetividades.

A constituição de cada sujeito acomoda a plurivocidade, a plasticidade e a heterogeneidade. Nesse sentido, há equívoco quando se ressaltam noções que procuram explicar que os aprendizes - em uma "totalidade homogênea" - devem aprender a escrever seguindo, de maneira estável e previsível, uma organização e uma cronologia lineares, genéricas e generalizantes. Essas noções, que padronizam atividades humanas, desconsideram as singularidades estabelecidas entre os sujeitos e a linguagem. Da mesma forma, não aceitam ritmos e atividades variáveis na apropriação da escrita, corroborando a homogeneização e normalização do processo de aprendizagem, uma vez que negam diferenças individuais, culturais e sociais evidenciadas nesse processo. Acrescentamos que os resultados encontrados, tanto nos exames de neuroimagem quanto nos exames genéticos, não podem ser generalizados como causa da dislexia, considerando, também, que a atipia cerebral pode ocorrer devido à ausência de práticas sociais de letramento.

A significação dos sintomas ditos patológicos não é, portanto, nem casual nem arbitrária. A prática clínica apenas reproduz e "naturaliza" esses conceitos. O uso destes acaba por evidenciar um campo estruturado em dois polos antagônicos - de um lado, as ciências médicas, de outro, as ciências humanas - que representam as interpretações que são feitas em torno do que possa ou não ocorrer, durante o processo de aquisição da escrita.

Convém destacar que não é apenas a descrição ou a conceituação de termos como "dislexia" o que está em questão (já que podem ser facilmente descontruídos, a depender da concepção que se tem), mas sim o que representa a adoção desses termos e as implicações disso para os sujeitos e para sociedade na qual estão inseridos.

Essas implicações promovem distintas posições: de um lado, a deficiência e a busca da cura autorizada por uma clínica, e de outro, o direito à diferença. Dito de outra forma, de um lado, temos um viés organicista que concebe um sujeito que "falha", mas cujas dificuldades individuais podem ser sanadas por meio de reabilitação. De outro, um viés social que analisa as dificuldades desse sujeito como decorrentes de suas diferenças sociais e culturais, de suas práticas de letramento e do significado que a escrita apresenta para ele. Este sujeito não vai necessitar de uma intervenção clínica, pois não apresenta um distúrbio. Mas não significa, no entanto, que ações específicas não sejam necessárias. 
Posições opostas e formas de intervenção também opostas. Nesse sentido, a desconstrução da dislexia tem implicações significativas no modo como concebemos o sujeito, a aquisição da escrita, a normalidade e a patologia. Cabe, então, aos leitores deste artigo, como bem diz Bourdieu (1998), serem cúmplices ou críticos em relação às diferentes maneiras de interpretação da realidade e de intervenção sobre ela.

\section{Referências}

Abaurre, M. B. M. (1994). Indícios das primeiras reelaborações dos textos infantis. Anais do Seminário do GEL-USP, 41, 367-372.

Abaurre, M. B. M., Fiad, R. S., \& Mayrink-Sabinson, M. L. T. (1997). Cenas de aquisição da escrita: O sujeito e o trabalho com o texto. Campinas, SP: Mercado das Letras.

Abaurre, M. B. M., Mayrink-Sabinson, M. L. T., \& Fiad, R. S. (Orgs.). (2003). Estilo e gênero na aquisição da escrita. Campinas, SP: Komedi.

Ajuriaguerra, J. (1984). A dislexia em questão (M. R. C. Silva, Trad.). Porto Alegre: Artes Médicas.

Arduini, R. G., Capellini, S. A., \& Ciasca, S. M. (2006). Comparative study of the neuropsychological and neuroimaging evaluations in children with dyslexia. Arquivos de Neuro-Psiquiatria 64(2b), 369-375.

Bates, T. C., Lind, P. A., Luciano, M., Montgomery, G. W, Martin, N. G., \& Wright, M. J. (2009). Dyslexia and DYX1C1: Deficits in reading and spelling associated with a missense mutation. Molecular Psychiatry, 15(12), 1190-1196.

Befi-Lopes, D. M. (2008). Diagnóstico e princípios terapêuticos em distúrbio específico de linguagem: Do fenótipo para o genótipo. Anais do Congresso Brasileiro de Fonoaudiologia e Genética dos Distúrbios da Comunicação, 2, 72-75.

Berberian, A. P., \& Massi, G. (2006). Pais, filhos e letramento: Ressiginificação de histórias de leitura e escrita no contexto da fonoaudiologia. In A. P. Berberian, C. Morisde-Angelis, \& G. Massi (Orgs.), Letramento: Referências em saúde e educação (pp. 33-65). São Paulo: Plexus.

Blasi, H. F. (2006). Contribuições da psicolinguística ao estudo da dislexia. Tese de Doutorado não publicada, Universidade Federal de Santa Catarina, Florianópolis.

Bourdieu, P. (1998). A economia das trocas linguísticas (2a ed., S. Miceli e cols., Trads.). São Paulo: Ed. USP.

Broca, P. (1965). Remarques sur lê siège de la faculté du langage articulé. Suivies d'une observation d'aphémie. In H. Hecaen \& J. Dubois (Eds.), La naissance de la neuropsychologie du langage (pp. 61-91). Paris: Éditeur Flammarion.

Cagliari, L. C. (1989). Alfabetização e linguística. São Paulo: Scipione.

Cagliari, L. C. (1998). Alfabetizando sem o ba-bé-bi-bó-bi. São Paulo: Scipione.
Canguilhem, G. (1995). O normal e o patológico (4a ed., M. T. R. Barrocas, Trad.). Rio de Janeiro: Forense Universitária.

Capovilla, A. G. S., \& Capovilla, F. C. (2004). Etiologia, avaliação e intervenção em dislexia do desenvolvimento. In F. C. Capovilla(Org.) Neuropsicologia eaprendizagem: Uma abordagem multidisciplinar (2a ed., pp. 46-73). São Paulo: Memnon.

Capovilla, F. C. (2004). Processamento auditivo central: Demonstrando uma validade de uma bateria de triagem para crianças de 6 a 11 anos. In F. C. Capovilla (Org.), Neuropsicologia e aprendizagem: Uma abordagem multidisciplinar (2a ed., pp. 117-141). São Paulo: Memnon.

Castro, S. M. C., Salgado, C. A., Andrade, F. P., Ciasca, S. M., \& Carvalho, K. M. M. (2008). Controle visual em crianças com dislexia do desenvolvimento. Arquivo Brasileiro de Oftalmologia, 71(6), 837-840.

Condemarin, M., \& Blomquist, M. (1986). Dislexia: Manual de leitura corretiva (A. M. N. Machado, Trad.). Porto Alegre: Artmed.

Critchley, M. D. (1974). La dyslexie vraie et lês difficultés de lecture chez l'enfant. Toulouse, France: Privat.

Déjèrine, J. (1891). Contribuition to the anatomicalpathological and clinical study of the different varieties of word blindness. In P. Eling (Ed.), Reader in the history of aphasia (pp. 197-218). Amsterdan: Jonh Benjamins Publishing Company.

Fijalkow, J., \& Ragano, S. (2004). Dyslexie: Le retour. Análise Psicológica, 22(1), 175-185.

Fonseca, V. (1995). Introdução às dificuldades de aprendizagem. Porto Alegre: Artmed.

Foucault, M. (2001). O nascimento da clínica (R. Machado, Trad.). Rio de Janeiro: Forense Universitária.

Foucault, M. (1994). Vigiar e punir (11a ed., R. Ramalhete, Trad.). Rio de Janeiro: Vozes.

Franchi, C. (1992). Linguagem: Atividade constitutiva. Cadernos de Estudos Linguísticos, (22), 9-39.

Freire, R. M. (2007). A metáfora da dislexia. In C. O. Lopes Filho (Org.), Tratado de fonoaudiologia (pp. 925-937). São Paulo: Roca.

Galaburda, A. M., LoTurco, J., Ramus, F., Fitch, H., \& Rosen, G. D. (2006). La dislexia del desarrollo: Gen, cerebro y cognición. Psykhe, 15(2), 3-11.

Grégoire, J., \& Piérart, B. (1997). Avaliação dos problemas de leitura: Os novos modelos teóricos e suas implicações diagnósticas. Porto Alegre: Artmed.

Hout, A. V. (2001). Distúrbios do movimento ocular. In A. V. Hout \& F. Estiene (Orgs.), Dislexias: Descrição, avaliação, explicação e tratamento (pp. 187-189). Porto Alegre: Artmed.

Índice Nacional de Alfabetismo Funcional. (2007). Recuperado em 10 novembro 2009, de http://epoca. globo.com/edic/499/INAF_2007_dez07.pdf 
Kassar, M. C. M. (2000.) Marcas da história social no discurso de um sujeito: Uma contribuição para a discussão a respeito da constituição social da pessoa com deficiência. Cadernos CEDES, 20(50), 41-54.

Kleiman, A., \& Matencio, M. L. M (Orgs.). (2008). Letramento e formação do professor. São Paulo: Mercado das Letras.

Lahire, B. (1997). Sucesso escolar nos meios populares: As razões do improvável (R. A. Vasques \& S. Goldfeder, Trads). São Paulo: Ática.

Lanhez, M. E., \& Nico, M. A. (2002). Nem sempre é o que parece: Como enfrentar a dislexia e os fracassos escolares. São Paulo: Alegro.

Lei No. 4.095, de 1 de fevereiro de 2008. (2008, 1 de fevereiro). Estabelece as diretrizes a serem observadas na elaboração da lei orçamentária do município para o exercício de 2009 e dá outras providências. Barretos, SP: Prefeitura Municipal.

Lyan, G. R., Shaywitz, S. E., \& Shaywitz, B. A. (2003). Defining dyslexia, comorbidity, teachers' knowledge of language and reading: A definition of dyslexia. Annals of Dyslexia, 53(1), 1-14.

Lopez-Escribano, C. (2007). Contribuciones de la neurociencia al diagnóstico y tratamiento educativo de la dislexia del desarrollo. Revista de Neurología, 44(3), 173-180.

Luria, A. R. (1970). Traumatic aphasia: Its syndromes, psychology and treatment. New York: Mouton.

Massi, G. A. (2004). Dislexia ou processo de aquisição da escrita? Revista Distúrbios da Comunicação, 16(3), 355-369.

Massi, G. A. (2007). A dislexia em questão. São Paulo: Plexus.

Massi, G. A., \& Berberian, A. P. (2005). A clínica fonoaudiológica voltada aos chamados distúrbios de leitura e escrita: Uma abordagem constitutiva de linguagem. Revista da Sociedade Brasileira de Fonoaudiologia, 10(1), 43-52.

Mello, S. L. (2010). Prefácio. In M. H. S. Patto (Ed.), A produção do fracasso escolar: Histórias de submissão $e$ rebeldia (pp. 9-13). Itatiba, SP: Casa do Psicólogo.

Morato, E. (2006). Neurolinguística. In Introdução à linguística 2 (pp. 143-170). São Paulo: Cortez.

Moysés, M . A. A., \& Collares, C. A. L. (1992). A história não contada dos distúrbios de aprendizagem. Cadernos CEDES, (28), 31-47.

Novaes-Pinto, R. (2008). Dificuldades de encontrar palavras e produção de parafasias nas afasias e nas demências: Inferências para o estudo da organização e do acesso lexical. Projeto de Pesquisa submetido ao Departamento de Linguística para contratação em regime de dedicação exclusiva. Instituto de Estudos da Linguagem - Universidade Estadual de Campinas, Campinas, SP.
Pan, M. (2006). Letramento escolar e processos subjetivos. In A. P. Berberian, C. Moris-de-Angelis, \& G. Massi (Orgs.), Letramento: Referenciais para a saúde e educação (pp. 66-116). São Paulo: Plexus.

Patto, M. H. S. (2010). A produção do fracasso escolar: Histórias de submissão e rebeldia. Itatiba, SP: Casa do Psicólogo.

Pinker, S. (2002). Tábula rasa: A negação contemporânea da natureza humana (L. T. Mota, Trad.). São Paulo: Companhia das Letras.

Quirós, J. B., \& Della Cella, M. (1972). La dislexia en la niñez (3a ed.). Buenos Aires: Editorial Paidos.

Ribeiro, V. M. (Org.). (2004). Letramento no Brasil. São Paulo: Ação Educativa.

Rojo, R. (2009). Letramentos múltiplos, escola e inclusão social. São Paulo: Parábola.

Salles, J. F., Parente, M. A. M. P., \& Machado, S. M. (2004). As dislexias de desenvolvimento: Aspectos neuropsicológicos e cognitivos. Interações, 9(17), 109132.

Santana, A. P. (2002). Escrita e afasia. São Paulo: Plexus.

Santana, A. P. (2004). Idade crítica para aquisição da linguagem. Revista Distúrbios da Comunicação, 16(3), 343-354.

Santana, A. P. (2007). Surdez e linguagem: Reflexões neurolinguísticas sobre a surdez. São Paulo: Plexus.

Santos, C. C. (1987). Dislexia específica de evolução. São Paulo: Sarvier.

Sauer, L., Pereira, L. D., Ciasca, S. M., Pestun, M., \& Guerreiro, M. M. (2006). Processamento auditivo e SPECT em crianças com dislexia. Arquivos de NeuroPsiquiatria, 64(1), 108-111.

Selikowitz, M. (2001). Dislexia e outras dificuldades de aprendizagem. Rio de Janeiro: Revinter.

Signorini, I. (Org.). (2010). Gêneros catalisadores: Letramento e formação do professor. São Paulo: Parábola.

Giselle Massi é Professora Doutora da Universidade Tuiuti do Paraná.

Ana Paula de Oliveira Santana é Professora Doutora da Universidade Federal de Santa Catarina.

Recebido: $13 / 03 / 2010$

$1^{a}$ revisão: 03/11/2010

Aceite final: 02/02/2011 